\title{
Quality of life in patients with primary hypothyroidism related to BMI
}

\author{
Nienke Kelderman-Bolk ${ }^{1,+}$, Theo J Visser ${ }^{2}$, Jan P Tijssen ${ }^{3}$ and Arie Berghout ${ }^{1}$ \\ ${ }^{1}$ Department of Internal Medicine, Maasstad Hospital Rotterdam, Rotterdam, The Netherlands, \\ ${ }^{2}$ Department of Internal Medicine, Erasmus Medical Center Rotterdam, Rotterdam, The Netherlands and \\ ${ }^{3}$ Department of Cardiology, Academic Medical Center Amsterdam, Amsterdam, The Netherlands \\ ${ }^{\dagger}$ (N Kelderman-Bolk is now at Alrijne Hospital Leiderdorp, Simon Smitweg 1, 2353 GA Leiderdorp, The Netherlands)
}

Correspondence should be addressed to N Kelderman-Bolk Email nienkekelderman@ hotmail.com

\section{Abstract}

Objective: Many patients treated for primary hypothyroidism have an unexplained reduced quality of life (QOL). We studied the relation between $\mathrm{QOL}$ and various parameters in treated hypothyroid patients.

Design and methods: QOL analysis was done in 90 consecutive patients ( $77.8 \%$ females) treated for primary hypothyroidism. QOL was measured by the questionnaires Short-Form 36, Hospital Anxiety and Depression Scale and MFI20. Post hoc analysis was performed on the relation of QOL at baseline and BMI, thyroid hormones and other serum values. QOL in patients was also compared to the general population.

Results: QOL was decreased compared to the general population. We found an inverse relationship between QOL and BMI. A relationship between QOL and serum thyroid parameters or auto-antibodies could not be found. Higher sex hormone binding globulin (SHBG) levels corresponded with a better QOL, which is explained by the negative association of SHBG with body weight and BMI.

Conclusions: A decreased QOL in hypothyroid patients on thyroxine treatment is related to a higher body weight (BMI). Weight gain needs more attention in the treatment of hypothyroidism.

\section{Introduction}

Primary hypothyroidism is a frequent disorder in the general population, with a prevalence between 2 and $3 \%$ $(1,2)$. The symptoms of hypothyroidism vary widely and are related to a decreased function of the brain, muscles, heart and kidney $(3,4,5,6,7,8)$. Restoration of these functions is achieved by treatment with levothyroxine $\left(\mathrm{L}-\mathrm{T}_{4}\right)(3,5,8)$, which markedly improves the signs and symptoms of hypothyroidism.

However, numerous patients treated for primary hypothyroidism with $\mathrm{L}-\mathrm{T}_{4}$ still complain of a reduced quality of life (QOL), despite serum thyroid hormone (TH) levels within the reference range $(9,10)$. A large study from western England showed that the QOL in a group of treated hypothyroid patients was indeed lower compared to controls of similar age and sex (9). In a study in
(C) 2015 European Society of Endocrinology Printed in Great Britain
Amsterdam in 141 hypothyroid patients, cognitive functioning, mental health and vitality were lower compared to a Dutch reference group (11).

There is no good explanation for the decreased QOL in hypothyroid patients who are euthyroid on $\mathrm{L}^{-\mathrm{T}_{4}}$ treatment. It seems plausible that there is a correlation between QOL and thyroid parameters (thyroid-stimulating hormone (TSH), free thyroxine $\left(\mathrm{FT}_{4}\right)$ and tri-iodothyronine $\left(T_{3}\right)$ ). Bearing this in mind, attempts have been made to improve QOL in treated patients, by, e.g., aiming at a lower serum TSH level during treatment (12), by adding liothyronine substitution to $\mathrm{L}^{-} \mathrm{T}_{4}(13,14)$, or by making small changes in the $\mathrm{L}^{-\mathrm{T}_{4}}$ dose (15). Until now, these attempts have not resulted in an improvement in well-being. 
Another aspect in the treatment of hypothyroidism is that serum $\mathrm{TH}$ levels may not represent $\mathrm{TH}$ levels in different tissues. In a study by Escobar-Morreale et al. (16) in hypothyroid rats, no single dose of $\mathrm{T}_{4}$ or $\mathrm{T}_{3}$ could restore euthyroidism in all tissues at the same time, probably because of varying expression and function of $\mathrm{TH}$ transporters and deiodinases. Sex hormone binding globulin (SHBG) is known to be a marker of hepatic $\mathrm{TH}$ state (17) and could be a useful parameter of $\mathrm{TH}$ status at tissue level.

As most patients with hypothyroidism in iodinereplete areas have auto-immune thyroiditis (18), autoimmunity per se could also be a cause of reduced QOL. A correlation between thyroid auto-antibodies and mood and depression has already been described by some authors $(19,20)$. Other factors, however, that we are still unaware of could contribute to the reduction in QOL of our hypothyroid patients.

We recently performed a double-blind randomized cross-over trial of the effects of morning vs bedtime $\mathrm{L}_{-} \mathrm{T}_{4}$ intake (21). During the trial, TH parameters changed within the same patient, with fluctuations just within or near the reference ranges. This is comparable to the average outpatient situation, where patients come to ask for the results of the laboratory tests. Often, based on the outcomes of these tests, the dosage of the thyroid hormonal supplementation is adapted. QOL in our patients, however, did not change, despite the changes in TH levels (16). During the trial thyroid parameters, markers of auto-immunity, vital parameters and QOL were assessed. This enabled us to investigate the correlation of these parameters with QOL in patients with primary hypothyroidism. In the discussion we will also review the literature on this subject.

\section{Subjects and methods}

\section{Subject selection and data collection}

A double-blind randomized cross-over trial over a period of 6 months was performed in consecutive patients with treated primary hypothyroidism in our outpatient clinic to evaluate the effect of morning vs bedtime $\mathrm{L}^{-\mathrm{T}_{4}}$ intake. The results of this trial were published earlier (21). In brief, patients older than 18 years of age and on a stable dose of $\mathrm{L}^{-\mathrm{T}_{4}}$ for at least 6 months were included. During the first 3 months, patients took $\mathrm{L}^{-} \mathrm{T}_{4}$ in the morning and placebo at night and switched to bedtime $\mathrm{L}^{-\mathrm{T}_{4}}$ and morning placebo for another 3 months (or vice versa). At inclusion, all patients were clinically assessed by an internist.
The Medical Ethics Committee of the Maasstad Hospital approved the study protocol, and written informed consent was obtained from each patient.

\section{Quality of life}

QOL was analysed by Short-Form 36 (SF-36), Hospital Anxiety and Depression Scale (HADS) and Multidimensional Fatigue Index 20 (MFI-20). Data at baseline are presented here, as our previous data (21) already showed that QOL did not change during the trial with morning vs bedtime $\mathrm{L}^{-\mathrm{T}_{4}}$ intake. Analyses at 3 and 6 months were performed but showed the same results.

Short-Form 36 SF-36 is a general QOL questionnaire that comprises eight scales: physical functioning, social functioning, role limitations (physical problems), role limitations (emotional problems), mental health, vitality, pain and general health perception. Scores per scale range from 0 to 100, the highest score indicating the best state of health (22).

Hospital Anxiety and Depression Scale - The HADS consists of 14 items pertaining to anxiety and depression. Scores for the anxiety and depression subscale range from 0 to 21 and for the total score from 0 to 42 . A higher score reflects more severe anxiety and depression (23).

Multidimensional Fatigue Index 20 The MFI-20 contains 20 statements to assess fatigue. From these statements, five different dimensions of fatigue are calculated: general fatigue, physical fatigue, reduced activity, reduced motivation and mental fatigue. Scores vary between 0 and 20. Higher scores correlate with more fatigue (24).

QOL scores at baseline were compared to scores in healthy control subjects $(n=440)$ derived from previous studies in Leiden University Medical Center (a hospital in the same region as Rotterdam) on pituitary disorders (25). In addition to this control group, we used reference data from healthy subjects of the Dutch and Western European population, obtained from studies reporting normal ageadjusted values $(22,26,27)$.

\section{Blood sampling}

Serum TSH levels (reference range $0.4-4.0 \mathrm{mU} / \mathrm{l}$ ) were measured by immunometric assay (Immulite 2000, DPC, Breda, The Netherlands), and $\mathrm{FT}_{4}$ (reference range 10-24 pmol/1, equivalent with $0.78-1.86 \mathrm{ng} / \mathrm{dl}$ ) and $\mathrm{T}_{3}$ (reference range $1.23-2.80 \mathrm{nmol} / 1$, equivalent with 
80-182 ng/dl) by competitive immunoassay (Immulite 2000, DPC).

SHBG, a marker of hepatic TH status (reference range men 14.5-48.4 nmol/1, premenopausal women 26.1$110 \mathrm{nmol} / \mathrm{l}$ and postmenopausal women 14.1-68.9 nmol/l), was measured by immunoassay (Cobas 6000, Roche Diagnostics).

Anti-thyroid peroxidase (TPO) antibodies were measured by ELISA (ImmunoCAP, Phadia AB, Uppsala, Sweden; > $60 \mathrm{IU} / 1$ considered positive) and anti-TSH receptor (TSHR) antibodies by radio-receptor assay (BRAHMS Diagnostica GmbH, Berlin, Germany; > 14 U/1 considered positive). As auto-immune hypothyroidism is often associated with other autoimmune disorders, we also tested for antibodies to parietal cells (PC), present in pernicious anaemia, by ELISA and immunofluorescence (Phadia $\mathrm{AB} ;>15 \mathrm{U} / \mathrm{l}$ considered positive), and antibodies to tissue transglutaminase (tTG), present in celiac disease, by ELISA (ImmunoCAP, Phadia AB; > $10 \mathrm{U} / \mathrm{ml}$ considered positive).

\section{Statistical analysis}

All calculations were done using SPSS 20.0 for Windows. All $P$ values were two-sided. Multiple associations between QOL and various parameters were studied in retrospect, because of which correction for multiple testing was difficult and was not performed. We used independent samples $t$-tests (equal variances not assumed) to compare patient and control data. Literature reference data used were weighted means according to the age distribution in our cohort and an unpaired $t$-test was used to compare means. The thyroid parameters were categorized in quartiles, and SHBG and BMI in tertiles, before univariate ANOVA analysis. As SHBG reference values vary with sex and age (men/women, below/above 50 years of age), patients were divided in tertiles (low, normal or high SHBG) per category. To investigate the relationships of QOL with TH, SHBG and BMI, a one-way ANOVA was performed $(P$ value for trend). Linear regression analysis was performed on the relation between QOL and BMI, unadjusted and adjusted for age, sex and TSH.

Clinical trial registration number: ISRCTN17436693.

\section{Results}

From April 2007 through June 2008, 90 patients with primary hypothyroidism were included in the trial and had adequate data for analysis. The mean age was 48 years (s.D. 11.7), mean BMI $29.1 \mathrm{~kg} / \mathrm{m}^{2}$ (s.D. 5.1 ) and $77.8 \%$ was females (Table 1).
Table 1 Baseline characteristics of treated hypothyroid patients $(n=90)$.

Age (years), mean (s.D.)
Female (\%)
BMI, mean (s.D.)
Duration hypothyroidism
(years), median (range)
Cause hypothyroidism ( $n$ )
Autoimmune (Hashimoto)
131,
Thyroidectomy
Neck radiation
Dose L-T ( $\mu$ g), median (range)
TSH (mU/l), mean (s.D.) $_{\text {FT }}($ pmol/l), mean (s.D.)
$\mathrm{FT}_{3}(\mathrm{nmol} / \mathrm{l})$, mean (s.D.)
a-TPO, $n(\%)$
a-TSHR, $n(\%)$
a-PC, $n(\%)$
a-TG, $n(\%)$

$48(11.7)$

77.8

$29.1(5)$

$2.5(0.5-25)$

52
34
3
1
$125(50-250)$
$2.38(2.55)$
$19.8(3.40)$
$1.96(0.53)$
$61(68)$
$10(11)$
$12(13)$
$0(0)$

${ }^{131} \mathrm{I}$, radioactive iodide therapy; a-TPO, anti-thyroid peroxidase; a-TSHR, anti-TSH receptor; a-PC, anti-parietal cells; a-TG, anti-transglutaminase.

\section{QOL in the study population}

QOL at baseline was impaired on all scales, as is shown in Table 2. There was no difference in QOL with morning or bedtime intake of $\mathrm{L}^{-} \mathrm{T}_{4}$, as was described in our previous paper (21). There was no difference in QOL according to the etiology of the hypothyroidism or duration of treatment ( $<1,1-5$ and $>5$ years; data not shown).

\section{QOL and TH parameters}

QOL measured by the three questionnaires was not dependent on serum TSH, $\mathrm{FT}_{4}$ (Tables 3 and 4) and $\mathrm{T}_{3}$ (data not shown). As described in our previous paper (21), QOL scores did not change with morning or bedtime $\mathrm{L}^{-\mathrm{T}_{4}}$ intake, despite the significant change in thyroid parameters.

\section{QOL and BMI}

BMI in the study population (BMI $29.1 \mathrm{~kg} / \mathrm{m}^{2}$ ) was higher than in the general Dutch population (mean BMI women $25.1 \mathrm{~kg} / \mathrm{m}^{2}$ and mean BMI men $26.0 \mathrm{~kg} / \mathrm{m}^{2}$ ) (29). QOL decreased with increasing body weight and, consequently, an increasing BMI in 11 out of 15 subscales of QOL (Table 5 and Supplemental Figure 1, see section on supplementary data given at the end of this article). The SF-36 questionnaire revealed more problems with physical functioning, role limitations due to physical problems, vitality, pain and general health at a higher BMI. The 
Table 2 QOL in study population compared to controls and reference data. QOL scores at baseline were compared to scores in healthy control subjects derived from previous studies in Leiden University Medical Center (a hospital in the same region as Rotterdam) on pituitary disorders (25). In addition to this control group, we used reference data from healthy subjects of the Dutch and Western European population, obtained from studies reporting normal age-adjusted values $(22,26,27)$.

\begin{tabular}{|c|c|c|c|c|c|}
\hline & $\begin{array}{l}\text { Study population } \\
(n=90) \text {, mean (s.D.) }\end{array}$ & $\begin{array}{c}\text { Controls }(n=440), \\
\text { mean (s.D.) }\end{array}$ & $P$ value* & $\begin{array}{c}\text { Age-adjusted reference } \\
\text { values }^{a} \text {, mean }\end{array}$ & $\boldsymbol{P}_{\text {value }}^{\dagger}$ \\
\hline \multicolumn{6}{|l|}{ SF-36 } \\
\hline Physical functioning & 64 (19) & 88 (17) & $<0.001$ & 81 & $<0.001$ \\
\hline Social functioning & $69(26)$ & 88 (19) & $<0.001$ & 87 & $<0.001$ \\
\hline Role limits: physical & $60(41)$ & $84(31)$ & $<0.001$ & 79 & $<0.001$ \\
\hline Role limits: emotional & $76(39)$ & $87(29)$ & 0.01 & 85 & 0.03 \\
\hline Mental health & 68 (19) & & & 77 & $<0.001$ \\
\hline Vitality & $51(22)$ & & & 67 & $<0.001$ \\
\hline Pain & $74(26)$ & 86 (19) & $<0.001$ & 80 & 0.047 \\
\hline General health & $55(22)$ & 72 (19) & $<0.001$ & 70 & $<0.001$ \\
\hline \multicolumn{6}{|l|}{ HAD } \\
\hline Anxiety & $6.7(4.3)$ & $4.1(3.2)$ & $<0.001$ & 4.99 & 0.001 \\
\hline Depression & $5.4(4.0)$ & $2.8(2.9)$ & $<0.001$ & 3.52 & $<0.001$ \\
\hline Total & $12(7.6)$ & $6.8(5.3)$ & $<0.001$ & 8.41 & $<0.001$ \\
\hline \multicolumn{6}{|l|}{ MFI-20 } \\
\hline General fatigue & $12.6(5.2)$ & $8.5(4.0)$ & $<0.001$ & 9.9 & $<0.001$ \\
\hline Physical activity & $12.6(4.9)$ & $7.6(3.7)$ & $<0.001$ & 8.8 & $<0.001$ \\
\hline Reduced activity & $11(4.4)$ & $7.2(3.5)$ & $<0.001$ & 8.7 & $<0.001$ \\
\hline Reduced motivation & $10.2(4.2)$ & $7.3(3.4)$ & $<0.001$ & 8.2 & $<0.001$ \\
\hline Mental fatigue & $10.4(5.2)$ & $7.8(3.9)$ & $<0.001$ & 8.3 & $<0.001$ \\
\hline
\end{tabular}

* $P$ value, patients compared with controls and ${ }^{\dagger} P$ value, patients compared with literature reference data. ${ }^{a}$ Derived from references $(22,26,27)$.

HADS questionnaire showed higher scores for depression, not anxiety. The MFI-20 questionnaire showed more fatigue at a higher BMI on all five different dimensions of fatigue. There was no relation between etiology of hypothyroidism or duration of treatment and BMI (data not shown).
No relationship was found between BMI and the thyroid parameters. Adjusting for the confounding factors age, sex and TSH did not change the relation between QOL and BMI as assessed by linear regression analysis (Supplemental Table 1, see section on supplementary data given at the end of this article ).

Table 3 TSH (mU/l) levels at baseline in quartiles related to QOL in treated hypothyroid patients.

\begin{tabular}{|c|c|c|c|c|c|}
\hline & \multicolumn{4}{|c|}{ TSH (mean (s.D.)) } & \multirow{2}{*}{$\begin{array}{l}P \text { value } \\
\text { for trend }\end{array}$} \\
\hline & $<0.72(n=22)$ & 0.72 to $<1.5(n=23)$ & 1.5 to $<3.3(n=23)$ & $>3.3(n=22)$ & \\
\hline \multicolumn{6}{|l|}{ SF-36 questionnaire } \\
\hline Physical functioning & $66(22)$ & 59 (18) & $65(20)$ & $65(17)$ & 0.95 \\
\hline Social functioning & $67(24)$ & $63(26)$ & $82(22)$ & $65(28)$ & 0.61 \\
\hline Role: physical & $65(42)$ & $53(42)$ & $62(44)$ & $62(39)$ & 0.99 \\
\hline Role: emotional & $85(34)$ & $68(44)$ & $80(37)$ & $70(38)$ & 0.37 \\
\hline Emotional wellbeing & 70 (17) & $62(20)$ & 77 (13) & $62(22)$ & 0.66 \\
\hline Vitality & 52 (19) & $42(23)$ & $58(25)$ & $50(18)$ & 0.53 \\
\hline Pain & $76(30)$ & $77(23)$ & $72(27)$ & $74(26)$ & 0.69 \\
\hline General health & $55(24)$ & $53(22)$ & $58(21)$ & $55(22)$ & 0.92 \\
\hline \multicolumn{6}{|l|}{ HADS } \\
\hline Depression & $4.8(3.7)$ & $6.3(4.4)$ & $4.7(3.3)$ & $5.8(4.1)$ & 0.69 \\
\hline Anxiety & $6.2(41)$ & $7.4(5.0)$ & $5.6(4.2)$ & $7.4(3.9)$ & 0.68 \\
\hline Total & $11.0(7.2)$ & $13.7(8.9)$ & $10.2(6.7)$ & $13.0(7.2)$ & 0.72 \\
\hline \multicolumn{6}{|l|}{ MFI-20 } \\
\hline General fatigue & $13.1(5.5)$ & $14.4(4.1)$ & $9.8(5.5)$ & $13.1(4.5)$ & 0.32 \\
\hline Physical fatigue & $12.4(5.1)$ & $14.0(4.1)$ & $11.0(5.7)$ & $13.0(4.6)$ & 0.82 \\
\hline Mental fatigue & $11.1(5.4)$ & $11.4(4.2)$ & $9.2(5.4)$ & $9.8(5.7)$ & 0.22 \\
\hline Reduced activity & $10.7(4.6)$ & $12.2(3.6)$ & $10.2(5.4)$ & $10.8(3.8)$ & 0.67 \\
\hline Reduced motivation & $9.2(4.2)$ & $11.7(4.0)$ & $9.2(4.4)$ & $10.4(3.9)$ & 0.79 \\
\hline
\end{tabular}


Table $4 \mathrm{FT}_{4}(\mathrm{pmol} / \mathrm{l})$ levels at baseline in quartiles related to QOL in treated hypothyroid patients.

\begin{tabular}{|c|c|c|c|c|c|}
\hline & \multicolumn{4}{|c|}{$\mathbf{F} \mathbf{T}_{\mathbf{4}}($ mean (s.D.)) } & \multirow{2}{*}{$\begin{array}{l}P \text { value for } \\
\text { trend }\end{array}$} \\
\hline & $<17.5(n=21)$ & 17.5 to $<20.2(n=24)$ & 20.2 to $<21.4(n=22)$ & $>21.4(n=23)$ & \\
\hline \multicolumn{6}{|l|}{ SF-36 questionnaire } \\
\hline Physical functioning & $61(19)$ & $64(18)$ & $68(22)$ & $64(17)$ & 0.35 \\
\hline Social functioning & $70(24)$ & $71(28)$ & $74(23)$ & $63(28)$ & 0.47 \\
\hline Role: physical & $54(43)$ & $57(41)$ & $73(42)$ & $60(40)$ & 0.38 \\
\hline Role: emotional & $81(37)$ & $68(42)$ & $89(24)$ & $70(43)$ & 0.77 \\
\hline Emotional wellbeing & $71(20)$ & $67(20)$ & $70(16)$ & $66(18)$ & 0.50 \\
\hline Vitality & $52(22)$ & $52(19)$ & $53(21)$ & $47(25)$ & 0.54 \\
\hline Pain & $78(27)$ & $77(24)$ & $75(26)$ & $68(29)$ & 0.22 \\
\hline General health & $57(23)$ & $49(18)$ & $64(21)$ & $53(24)$ & 0.80 \\
\hline \multicolumn{6}{|l|}{ HADS } \\
\hline Depression & $4.9(4.3)$ & $6.1(3.7)$ & $4.1(2.6)$ & $6.2(4.5)$ & 0.66 \\
\hline Anxiety & $5.7(3.9)$ & $7.4(4.8)$ & $6.1(3.9)$ & $6.9(4.3)$ & 0.66 \\
\hline Total & $10.4(7.2)$ & $13.5(8.0)$ & $10.1(5.7)$ & $13.1(8.4)$ & 0.55 \\
\hline \multicolumn{6}{|l|}{ MFI-20 } \\
\hline General fatigue & $12.0(4.6)$ & $12.1(4.8)$ & $12.1(5.5)$ & $13.7(5.6)$ & 0.31 \\
\hline Physical fatigue & $12.2(4.8)$ & $12.5(4.6)$ & $11.7(5.4)$ & $13.7(5)$ & 0.51 \\
\hline Mental fatigue & $10.0(5.1)$ & $10.0(5.3)$ & $10.5(5.5)$ & $10.5(4.9)$ & 0.77 \\
\hline Reduced activity & $11.2(5.1)$ & $10.2(4.3)$ & $10.4(4.2)$ & $12.0(4.1)$ & 0.59 \\
\hline Reduced motivation & $10.7(4.4)$ & $9.6(3.9)$ & $9.3(3.8)$ & $11.2(4.7)$ & 0.72 \\
\hline
\end{tabular}

\section{QOL and SHBG}

A higher SHBG, a marker of hepatic TH status, corresponded with a better QOL in nine out of the 15 subscales (Table 6). An improvement in QOL was seen in physical functioning, role limitations due to emotional problems, vitality, pain and general health, according to the SF-36 questionnaire. The HADS revealed an improvement in depression scores with higher SHBG levels, and the MFI-20 showed a reduction in physical fatigue, in reduced activity and in reduced motivation. $\mathrm{SHBG}$ was not related to $\mathrm{FT}_{4}$ or $\mathrm{T}_{3}$ levels.

An increase in SHBG corresponded with a decrease in BMI. A low, normal and high SHBG corresponded with a BMI of $31.0,30.1$ and $26.3 \mathrm{~kg} / \mathrm{m}^{2}$ respectively $(P<0.001)$. When corrected for BMI, the correlation between SHBG and QOL disappeared in the above-mentioned QOL scales, except for SF-36 role limitations due to emotional problems and MFI-20 reduced motivation scale.

Table 5 QOL at baseline in normal weight, overweight and obese patients treated for hypothyroidism. Data are presented as mean (s.D.).

\begin{tabular}{|c|c|c|c|c|}
\hline & $\begin{array}{l}\text { Normal weight } \\
\text { (BMI: }<25 ; n=21 \text { ) }\end{array}$ & $\begin{array}{c}\text { Overweight } \\
\text { (BMI: } 25 \text { to }>30 ; n=31 \text { ) }\end{array}$ & $\begin{array}{c}\text { Obese } \\
\text { (BMI: }>30 ; n=38)\end{array}$ & $\begin{array}{l}P \text { value } \\
\text { for trend }\end{array}$ \\
\hline \multicolumn{5}{|l|}{ SF-36 questionnaire } \\
\hline Physical functioning & 77 (13) & $61(19)$ & $60(16)$ & 0.001 \\
\hline Social functioning & $76(27)$ & $72(23)$ & $64(26)$ & 0.10 \\
\hline Role: physical & $86(31)$ & $60(39)$ & $49(43)$ & 0.001 \\
\hline Role: emotional & $85(30)$ & 77 (35) & 72 (44) & 0.22 \\
\hline Emotional wellbeing & 69 (18) & 70 (13) & $67(22)$ & 0.68 \\
\hline Vitality & $62(19)$ & $48(24)$ & $47(20)$ & 0.01 \\
\hline Pain & $90(20)$ & $69(26)$ & $71(27)$ & 0.007 \\
\hline General health & $68(20)$ & $55(21)$ & $50(22)$ & 0.003 \\
\hline \multicolumn{5}{|l|}{ HADS } \\
\hline Depression & $3.8(3.2)$ & $5.2(3.0)$ & $6.3(4.6)$ & 0.02 \\
\hline Anxiety & $6.3(4.2)$ & $6.7(4.0)$ & $6.5(4.5)$ & 0.83 \\
\hline Total & $10.0(7.0)$ & $11.9(6.4)$ & $12.7(8.4)$ & 0.21 \\
\hline \multicolumn{5}{|l|}{ MFI-20 } \\
\hline General fatigue & $10.7(4.9)$ & $12.9(5.3)$ & $13.2(4.9)$ & 0.08 \\
\hline Physical fatigue & $9.4(4.9)$ & $12.5(4.9)$ & $14.0(4.3)$ & 0.001 \\
\hline Mental fatigue & $7.7(4.0)$ & $11.0(4.5)$ & $11.0(5.7)$ & 0.02 \\
\hline Reduced activity & $8.0(3.4)$ & $11.2(5.1)$ & $12.2(3.7)$ & 0.001 \\
\hline Reduced motivation & $8.0(3.8)$ & $10.6(4.3)$ & $11.0(4.1)$ & 0.01 \\
\hline
\end{tabular}


Table 6 SHBG at baseline in tertiles related to QOL parameters. SHBG was divided in tertiles in the different populations (men, women $<50$ years, women $>50$ years). These tertiles were categorized as low, normal and high SHBG respectively. The tertiles of SHBG were related to QOL questionnaires in treated hypothyroid patients.

\begin{tabular}{|c|c|c|c|c|}
\hline & \multicolumn{3}{|c|}{ SHBG (mean (s.D.)) } & \multirow[b]{2}{*}{$P$ value for trend } \\
\hline & Low $(n=30)$ & Normal $(n=30)$ & High $(n=30)$ & \\
\hline \multicolumn{5}{|l|}{ SF-36 } \\
\hline Physical functioning & $58(22)$ & $62(15)$ & $71(18)$ & 0.02 \\
\hline Social functioning & $68(22)$ & $60(28)$ & $78(23)$ & 0.11 \\
\hline Role: physical & $58(44)$ & $49(40)$ & $73(37)$ & 0.16 \\
\hline Role: emotional & $64(44)$ & $69(42)$ & $93(19)$ & 0.004 \\
\hline Emotional wellbeing & 68 (19) & $63(21)$ & $73(16)$ & 0.29 \\
\hline Vitality & $45(24)$ & $45(17)$ & $60(21)$ & 0.008 \\
\hline Pain & $67(29)$ & $69(26)$ & 87 (19) & 0.004 \\
\hline General health & $53(22)$ & $47(19)$ & $66(22)$ & 0.02 \\
\hline \multicolumn{5}{|l|}{ HADS } \\
\hline Depression & $5.9(4.3)$ & $6.3(3.8)$ & $3.9(3.3)$ & 0.047 \\
\hline Anxiety & $7.1(4.4)$ & $7.4(4.4)$ & $5.5(4.2)$ & 0.14 \\
\hline Total & $13.1(8.0)$ & $13.6(7.3)$ & $9.4(6.9)$ & 0.06 \\
\hline \multicolumn{5}{|l|}{ MFI-20 } \\
\hline General fatigue & $13.0(4.7)$ & $13.7(5.0)$ & $11.3(5.5)$ & 0.21 \\
\hline Physical fatigue & $13.3(4.8)$ & $14.1(4.0)$ & $10.7(5.4)$ & 0.04 \\
\hline Mental fatigue & $10.1(4.6)$ & $11.9(5.3)$ & $9.3(5.4)$ & 0.55 \\
\hline Reduced activity & $12.2(4.5)$ & $11.5(3.6)$ & $9.3(4.6)$ & 0.01 \\
\hline Reduced motivation & $10.7(4.3)$ & $11.8(4.1)$ & $8.3(3.5)$ & 0.03 \\
\hline
\end{tabular}

\section{QOL and autoimmunity}

In 61 patients (68\%), TPO antibodies were found, and ten patients (11\%) had TSHR antibodies. Twelve patients had PC antibodies (positive by both immunofluorescence and ELISA) and none of the patients had tTG antibodies. No relationship was found between QOL and any of these antibodies.

\section{QOL compared to external controls}

QOL in our study population was compared to QOL in healthy controls (Leiden controls, $n=440$ ) by SF-36, HADS and MFI-20 questionnaires (Table 2). The Leiden control group had a similar sex distribution, but was 3 years older than our patient group $(P=0.04)$. SF-36 scores in hypothyroid patients were markedly lower than in controls in all eight subscales, indicating a worse general QOL. Scores on the HADS and MFI-20 questionnaires were higher compared to the reference values, indicating more depression and anxiety, and fatigue respectively.

A comparison of QOL scores in hypothyroid patients with age-adjusted reference values from previous studies confirmed the reduced QOL in the study population on all the measured subscales (Table 2).

\section{Discussion}

In this study, we found that in treated hypothyroid patients, QOL was not related to the serum levels of TSH,
$\mathrm{FT}_{4}$ or $\mathrm{T}_{3}$. This reinforces results from other studies, in which no correlation between QOL and thyroid parameters could be found. For example, a study on the starting dose of $\mathrm{L}^{-} \mathrm{T}_{4}$ in newly diagnosed hypothyroidism found a faster normalization of thyroid parameters with a high starting dose of $\mathrm{L}^{-} \mathrm{T}_{4}$ compared with an incremental dose regimen, but did not find a faster improvement of QOL (30). Two studies on the influence of small changes in $\mathrm{L}_{-} \mathrm{T}_{4}$ doses, and thus TH levels, could not find changes in well-being, hypothyroid symptoms, or QOL $(15,31)$. Our findings could have consequences for clinical practice as more than often $\mathrm{L}^{-\mathrm{T}_{4}}$ dosages are adjusted based on the suggested relationship of patient complaints about QOL and $\mathrm{TH}$ levels just within or outside the normal reference range.

Interestingly, a decreased QOL was related to increasing body weight and BMI. Overweight is probably an overlooked aspect in patients with hypothyroidism, and could be a large contributor to the reduced QOL. In a study on reduced QOL in treated hypothyroid patients, putting on weight was significantly more often indicated as a problem by patients than by healthy controls (9). Even after therapy is started and the excess body water that is associated with myxedema in hypothyroidism is lost (32), the weight often remains a problem. Several studies have indeed demonstrated that body weight of patients with primary or iatrogenic hypothyroidism increases over the years $(33,34,35)$. The greater weight gain described in the studied subjects compared to age- and gender-matched 
controls, is not due to inadequately normalized TSH values $(9,35)$. Possible causes of weight gain in hypothyroid patients may include a failure of $\mathrm{L}_{-} \mathrm{T}_{4}$ to serve as a full replacement for THs. Although $\mathrm{FT}_{4}$ and $\mathrm{T}_{3}$ levels are adequately normalized by $\mathrm{L}^{-\mathrm{T}_{4}}$ mono-therapy (36), it is difficult to mimic normal hormone secretion by hormonal substitution therapy in hypothyroid patients (37). In a trial comparing combined $\mathrm{T}_{4} / \mathrm{T}_{3}$ treatment with $\mathrm{L}-\mathrm{T}_{4}$ monotherapy, there was a preference of patients for combination therapy if they lost weight (11). A similar patient preference for desiccated $\mathrm{TH}$ over $\mathrm{L}_{\mathrm{T}} \mathrm{T}_{4}$ was also connected to weight loss (33).

Obesity in general is known to decrease health-related QOL (38). Interestingly, in a Dutch study on QOL in obese and non-obese subjects, QOL in obese women was decreased on the same subscales as in our population (28). Besides the impact on QOL, obesity is also related to health problems such as hypertension, diabetes, cardiovascular disease and malignancy (39). Once people have gained weight, most interventions directed at weight loss are unsuccessful. It is therefore of the utmost importance to prevent weight gain by counselling patients and encouraging them to engage in weight loss programs. The experience of endocrinologists shows, however, that it is difficult to prevent and/or treat weight gain in hypothyroid patients. Further investigation is warranted on the cause of weight gain in (treated) hypothyroidism, which will hopefully improve treatment of hypothyroid patients in the future.

SHBG is known to be a marker of hepatic TH state (17). In our study, a higher SHBG corresponded with a better QOL on various subscales. However, this relationship of SHBG with QOL disappeared in most of the subscales after correction for BMI. The level of SHBG varies with nutritional status (and thus BMI), age and sex hormones, which interferes with its use as a sensitive parameter of $\mathrm{TH}$ action (40). As the majority of hypothyroid patients are female (with fluctuations in estrogen levels during life), SHBG is not a suitable marker of TH status. In fact, TSH itself is an indicator of tissue TH levels because of the feedback of $\mathrm{TH}$ on the hypothalamus-pituitary-thyroid axis. However, as mentioned before, TSH did not show a correlation with QOL.

A relationship between QOL and thyroid autoantibodies, or antibodies associated with other autoimmune disorders was not found in our study population. Recently, some investigators found a relation between thyroid auto-antibodies and mood and depression in subjects with a normal thyroid function $(19,20)$. However, this is not confirmed by others (41), which is in line with our results. Perhaps the study population needs to be larger to draw definite conclusions on this matter. We found a much higher percentage of patients with PC antibodies than previously described in a population of patients with auto-immune hypothyroidism (13\% vs 4.5\%) (42). We, however, measured PC antibodies, irrespective of symptoms or anaemia, and not only in patients with self-reported pernicious anaemia, which is of course a smaller proportion of subjects.

In our study population, QOL was decreased compared to the general population (26). These findings confirm the reduced QOL found in previous studies of treated hypothyroid patients $(9,11)$. Comparing patients with chronic illnesses, QOL in hypothyroid patients is worse than in patients with diabetes mellitus (43), but better than in patients with fibromyalgia (44). It should be mentioned that QOL in our outpatient study population could be worse than QOL in hypothyroid patients in general, because of a referral bias of patients with more complaints towards an outpatient clinic. However, it is the experience of many clinicians, including general practitioners, that QOL-related problems tend to persist in treated hypothyroid patients.

In conclusion, in a large group of treated hypothyroid patients, we found a decreased QOL that was related to an increased body weight and BMI. QOL was not dependent on serum thyroid parameters or auto-antibodies. These findings are important, as an increase in body weight is a frequent finding in treated hypothyroid patients, and should have our attention in the treatment of hypothyroidism and in future research.

\section{Supplementary data}

This is linked to the online version of the paper at http://dx.doi.org/10.1530/ EJE-15-0395.

Declaration of interest

The authors declare that there is no conflict of interest that could be perceived as prejudicing the impartiality of the research reported.

\section{Funding}

This research did not receive any specific grant from any funding agency in the public, commercial or not-for-profit sector.

\section{References}

1 Flynn RW, MacDonald TM, Morris AD, Jung RT \& Leese GP. The thyroid epidemiology, audit, and research study: thyroid dysfunction in the general population. Journal of Clinical Endocrinology and Metabolism 200489 3879-3884. (doi:10.1210/jc.2003-032089) 
2 Carle A, Laurberg P, Pedersen IB, Knudsen N, Perrild H, Ovesen L, Rasmussen LB \& Jorgensen T. Epidemiology of subtypes of hypothyroidism in Denmark. European Journal of Endocrinology 2006 154 21-28. (doi:10.1530/eje.1.02068)

3 Bauer M, Silverman DH, Schlagenhauf F, London ED, Geist CL, van Herle K, Rasgon N, Martinez D, Miller K, van Herle A et al. Brain glucose metabolism in hypothyroidism: a positron emission tomography study before and after thyroid hormone replacement therapy. Journal of Clinical Endocrinology and Metabolism 200994 2922-2929. (doi:10.1210/ jc.2008-2235)

4 Simonides WS \& van Hardeveld C. Thyroid hormone as a determinant of metabolic and contractile phenotype of skeletal muscle. Thyroid 2008 18 205-216. (doi:10.1089/thy.2007.0256)

5 Tielens ET, Pillay M, Storm C \& Berghout A. Changes in cardiac function at rest before and after treatment in primary hypothyroidism. American Journal of Cardiology 200085 376-380. (doi:10.1016/S00029149(99)00750-X)

6 Grais IM \& Sowers JR. Thyroid and the heart. American Journal of Medicine 2014127 691-698. (doi:10.1016/j.amjmed.2014.03.009)

7 Rhee CM, Kalantar-Zadeh K, Streja E, Carrero JJ, Ma JZ, Lu JL \& Kovesdy CP. The relationship between thyroid function and estimated glomerular filtration rate in patients with chronic kidney disease. Nephrology, Dialysis, Transplantation 201530 282-287. (doi:10.1093/ ndt/gfu303)

8 den Hollander JG, Wulkan RW, Mantel MJ \& Berghout A. Correlation between severity of thyroid dysfunction and renal function. Clinical Endocrinology 200562 423-427. (doi:10.1111/j.1365-2265.2005.02236.x)

9 Saravanan P, Chau WF, Roberts N, Vedhara K, Greenwood R \& Dayan CM. Psychological well-being in patients on 'adequate' doses of L-thyroxine: results of a large, controlled community-based questionnaire study. Clinical Endocrinology 200257 577-585. (doi:10.1046/j. 1365-2265.2002.01654.x)

10 Watt T, Groenvold M, Rasmussen AK, Bonnema SJ, Hegedüs L, Bjorner JB \& Feldt-Rasmussen U. Quality of life in patients with benign thyroid disorders. A review. European Journal of Endocrinology 2006154 501-510. (doi:10.1530/eje.1.02124)

11 Wekking EM, Appelhof BC, Fliers E, Schene AH, Huyser J, Tijssen JG \& Wiersinga WM. Cognitive functioning and well-being in euthyroid patients on thyroxine replacement therapy for primary hypothyroidism. European Journal of Endocrinology 2005153 747-753. (doi:10.1530/eje.1.02025)

12 Hamilton TE, Davis S, Onstad L \& Kopecky KJ. Thyrotropin levels in a population with no clinical, autoantibody, or ultrasonographic evidence of thyroid disease: implications for the diagnosis of subclinical hypothyroidism. Journal of Clinical Endocrinology and Metabolism 200893 1224-1230. (doi:10.1210/jc.2006-2300)

13 Appelhof BC, Fliers E, Wekking EM, Schene AH, Huyser J, Tijssen JG, Endert E, van Weert HC \& Wiersinga WM. Combined therapy with levothyroxine and liothyronine in two ratios, compared with levothyroxine monotherapy in primary hypothyroidism: a double-blind, randomized, controlled clinical trial. Journal of Clinical Endocrinology and Metabolism 200590 2666-2674. (doi:10.1210/jc. 2004-2111)

14 Grozinsky-Glasberg S, Fraser A, Nahshoni E, Weizman A \& Leibovici L. Thyroxine-triiodothyronine combination therapy versus thyroxine monotherapy for clinical hypothyroidism: meta-analysis of randomized controlled trials. Journal of Clinical Endocrinology and Metabolism 200691 2592-2599. (doi:10.1210/jc.2006-0448)

15 Walsh JP, Ward LC, Burke V, Bhagat CI, Shiels L, Henley D, Gillett MJ, Gilbert R, Tanner M \& Stuckey BG. Small changes in thyroxine dosage do not produce measurable changes in hypothyroid symptoms, well-being, or quality of life: results of a double-blind, randomized clinical trial. Journal of Clinical Endocrinology and Metabolism 200691 2624-2630. (doi:10.1210/jc.2006-0099)

16 Escobar-Morreale HF, Obregon MJ, Escobar del Rey F \& Morreale de Escobar G. Replacement therapy for hypothyroidism with thyroxine alone does not ensure euthyroidism in all tissues, as studied in thyroidectomized rats. Journal of Clinical Investigation 199596 2828-2838. (doi:10.1172/JCI118353)

17 Selva DM \& Hammond GL. Thyroid hormones act indirectly to increase sex hormone-binding globulin production by liver via hepatocyte nuclear factor-4a. Journal of Molecular Endocrinology 200943 19-27. (doi:10.1677/JME-09-0025)

18 Vanderpump MP \& Tunbridge WM. Epidemiology and prevention of clinical and subclinical hypothyroidism. Thyroid 200212 839-847. (doi:10.1089/105072502761016458)

19 Vonk R, van der Schot AC, Kahn RS, Nolen WA \& Drexhage HA. Is autoimmune thyroiditis part of the genetic vulnerability (or an endophenotype) for bipolar disorder? Biological Psychiatry 200762 135-140. (doi:10.1016/j.biopsych.2006.08.041)

20 Carta MG, Loviselli A, Hardoy MC, Massa S, Cadeddu M, Sardu C, Carpiniello B, Dell'Osso L \& Mariotti S. The link between thyroid autoimmunity (antithyroid peroxidase autoantibodies) with anxiety and mood disorders in the community: a field of interest for public health in the future. BMC Psychiatry 2004425 . (doi:10.1186/ 1471-244X-4-25)

21 Bolk N, Visser TJ, Nijman J, Jongste IJ, Tijssen JG \& Berghout A. Effects of evening vs morning levothyroxine intake: a randomized doubleblind crossover trial. Archives of Internal Medicine 2010170 1996-2003. (doi:10.1001/archinternmed.2010.436)

22 Van der Zee KI \& Sanderman S. Het meten van de algemene gezondheidstoestand met de RAND-36, een handleiding. Tweede herziene druk. UMCG/Rijksuniversiteit Groningen, Research Institute SHARE. 2012 (www.rug.nl/share).

23 Zigmond AS \& Snaith RP. The hospital anxiety and depression scale. Acta Psychiatrica Scandinavica 198367 361-370. (doi:10.1111/j.16000447.1983.tb09716.x)

24 Smets EM, Garssen B, Bonke B \& De Haes JC. The Multidimensional Fatigue Inventory (MFI) psychometric qualities of an instrument to assess fatigue. Journal of Psychosomatic Research 199539 315-325. (doi:10.1016/0022-3999(94)00125-O)

25 van der Klaauw AA, Kars M, Biermasz NR, Roelfsema F, Dekkers OM, Corssmit EP, van Aken MO, Havekes B, Pereira AM, Pijl H et al. Diseasespecific impairments in quality of life during long-term follow-up of patients with different pituitary adenomas. Clinical Endocrinology 2008 69 775-784. (doi:10.1111/j.1365-2265.2008.03288.x)

26 Spinhoven P, Ormel J, Sloekers PP, Kempen GI, Speckens AE \& Van Hemert AM. A validation study of the Hospital Anxiety and Depression Scale (HADS) in different groups of Dutch subjects. Psychological Medicine 199727 363-370. (doi:10.1017/S0033291796004382)

27 Smets EM, Visser MR, Willems-Groot AF, Garssen B, SchusterUitterhoeve AL \& De Haes JC. Fatigue and radiotherapy: (B) experience in patients 9 months following treatment. British Journal of Cancer 1998 78 907-912. (doi:10.1038/bjc.1998.600)

28 Burns CM, Tijhuis MA \& Seidell JC. The relationship between quality of life and perceived body weight and dieting history in Dutch men and women. International Journal of Obesity and Related Metabolic Disorders 200125 1386-1392. (doi:10.1038/sj.ijo.0801714)

29 Blokstra A, Vissink P, Venmans LMAJ, Holleman P, van der Schouw YT, Smit HA \& Verschuren WMM. Measuring the Netherlands: A monitoring study of risk factors in the general population 2009-2010. RIVM rapport 260152001, 2011 (www.rivm.nl/nldemaat).

30 Roos A, Linn-Rasker SP, van Domburg RT, Tijssen JP \& Berghout A. The starting dose of levothyroxine in primary hypothyroidism treatment: a prospective, randomized, double-blind trial. Archives of Internal Medicine 2005165 1714-1720. (doi:10.1001/archinte.165.15.1714)

31 Carr D, McLeod DT, Parry G \& Thornes HM. Fine adjustment of thyroxine replacement dosage: comparison of the thyrotrophin releasing hormone test using a sensitive thyrotrophin assay with measurement of free thyroid hormones and clinical assessment. Clinical Endocrinology 198828 325-333. (doi:10.1111/j.1365-2265.1988.tb01219.x) 
32 Karmisholt J, Andersen S \& Laurberg P. Weight loss after therapy of hypothyroidism is mainly caused by excretion of excess body water associated with myxoedema. Journal of Clinical Endocrinology and Metabolism 201196 E99-103. (doi:10.1210/jc.2010-1521)

33 Hoogwerf BJ \& Nuttall FQ. Long-term weight regulation in treated hyperthyroid and hypothyroid subjects. American Journal of Medicine 198476 963-970. (doi:10.1016/0002-9343(84)90842-8)

34 Dale J, Daykin J, Holder R, Sheppard MC \& Franklyn JA. Weight gain following treatment of hyperthyroidism. Clinical Endocrinology 200155 233-239. (doi:10.1046/j.1365-2265.2001.01329.x)

35 Jonklaas J \& Nsouli-Maktabi H. Weight changes in euthyroid patients undergoing thyroidectomy. Thyroid 201121 1343-1351. (doi:10.1089/ thy.2011.0054)

36 Jonklaas J, Davidson B, Bhagat S \& Soldin SJ. Triiodothyronine levels in athyreotic individuals during levothyroxine therapy. Journal of the American Medical Association 2008299 769-777. (doi:10.1001/jama. 299.7.769)

37 Romijn JA, Smit JW \& Lamberts SW. Intrinsic imperfections of endocrine replacement therapy. European Journal of Endocrinology 2003 149 91-97. (doi:10.1530/eje.0.1490091)

38 Katz DA, McHorney CA \& Atkinson RL. Impact of obesity on healthrelated quality of life in patients with chronic illness. Journal of General Internal Medicine 200015 789-796. (doi:10.1046/j.1525-1497.2000. 90906.x)

39 Folsom AR, Kushi LH, Anderson KE, Mink PJ, Olson JE, Hong CP, Sellers TA, Lazovich D \& Prineas RJ. Associations of general and abdominal obesity with multiple health outcomes in older women: the
Iowa Women's Health Study. Archives of Internal Medicine $2000 \mathbf{1 6 0}$ 2117-2128. (doi:10.1001/archinte.160.14.2117)

40 Peter A, Kantartzis K, Machann J, Schick F, Staiger H, Machicao F, Schleicher E, Fritsche A, Häring HU \& Stefan N. Relationships of circulating sex hormone-binding globulin with metabolic traits in humans. Diabetes 201059 3167-3173. (doi:10.2337/ db10-0179)

41 Engum A, Bjoro T, Mykletun A \& Dahl AA. Thyroid autoimmunity, depression and anxiety; are there any connections? An epidemiological study of a large population Journal of Psychosomatic Research $2005 \mathbf{5 9}$ 263-268. (doi:10.1016/j.jpsychores.2005.04.002)

42 Boelaert K, Newby PR, Simmonds MJ, Holder RL, Carr-Smith JD, Heward JM, Manji N, Allahabadia A, Armitage M, Chatterjee KV et al. Prevalence and relative risk of other autoimmune diseases in subjects with autoimmune thyroid disease. American Journal of Medicine 2010 183 e181-e189. (doi:10.1016/j.amjmed.2009.06.030)

43 Kuznetsov L, Griffin SJ, Davies MJ, Lauritzen T, Khunti K, Rutten GE \& Simmons RK. Diabetes-specific quality of life but not health status is independently associated with glycaemic control among patients with type 2 diabetes: a cross-sectional analysis of the ADDITION-Europe trial cohort. Diabetes Research and Clinical Practice 2014104 281-287. (doi:10.1016/j.diabres.2013.12.029)

44 Salaffi F, Sarzi-Puttini P, Girolimetti R, Atzeni F, Gasparini S \& Grassi W. Health-related quality of life in fibromyalgia patients: a comparison with rheumatoid arthritis patients and the general population using the SF-36 health survey. Clinical and Experimental Rheumatology 200927 S67-S74.

Received 14 April 2015

Revised version received 21 June 2015

Accepted 13 July 2015 